\title{
Urban form Resilience Urban Design Practice: Masterplanning for Change
}

\author{
Ombretta Romice ${ }^{1}$, Sergio Porta ${ }^{2}$ and Alessandra Feliciotti ${ }^{3, *}$ \\ ${ }^{1}$ Senior Lecturer at Urban Design Studies Unit (UDSU), Department of Architecture, Faculty of \\ Engineering, University of Strathclyde. \\ ${ }^{2}$ Professor at UDSU, Department of Architecture, Faculty of Engineering, University of Strathclyde. \\ ${ }^{3}$ Research Associate at UDSU, Department of Architecture, Faculty of Engineering, University of \\ Strathclyde
}

E-Mails: ombretta.r.romice@strath.ac.uk; sergio.porta@strath.ac.uk; $\underline{\text { a.feliciotti@ @strath.ac.uk. }}$

* Author to whom correspondence should be addressed; Tel.: +44-(0)141 548 3171;

\begin{abstract}
The idea of cities as complex systems in constant adaptive change is finally engaging urban thinking. However, we are still far from having this idea guide practice. UNHabitat recognised this challenge in the "New Urban Agenda", establishing the link between configuration of places and their performance. However, we lag behind in understanding how urban places work from a resilience perspective, and urban planning and design are not ready to give directions for successful place-making, that works for people, the environment and the economy. We are in desperate need for something practical and yet theoretically new to answer to this challenge. The work presented in this short paper is our answer, and is based on joining the realms of design to that of resilience, an achievement possible only when treating urban form as a complex adaptive system per se. On these basis, we introduce an innovative approach to place-making - "masterplanning for change" which, learning from the rules that generated adaptive and successful places in history to date, calls for an urban design practice that designs places much less and much better, with implications for policymaking. Far from being an ideological manifesto, our approach is: 1) evidenced based: having learned to identify the recurrent successes of resilience from the observation of cities in history up to our days, it uses them to design the city of the future. 2) practical: it advocates a reformed process of place-making, and provides the tools to deliver it, making it an essential reference for designers and policy-makers.
\end{abstract}

Keywords: Adaptive masterplanning, resilience, urban design, place-making. 


\section{Cities as complex systems}

The study of complex systems - be these social, economic, physical or biological - has developed greatly in the last 50 years, with advancements in understanding both the nature and roles of their components, their relationships and behaviors (Holling, 1973; Cumming et al. 2005; Folke, 2006; Simmie and Martin, 2010; Feliciotti et al, 2016). Cities are also often referred to as complex systems (the first one to do so had been Jacobs in 1961), but are studied in this fashion predominantly from a social, ecological or economic points of view (Pickett et al., 2004). Urban form, the material which constitute all that is physically tangible in cities, has never been treated as a complex system itself, rather it is mostly seen as a "container" of life, actions and transactions. This is a fundamental mistake, because it prevents the design of the physical realm to be a main player itself in the conceptualization, production and management of the city as a complex system, which is, in turn, the only realistic and viable approach we can adopt to deal with todays and tomorrow's cities in contexts of uncertainty and unpredictability. This oversight needs overcome and the work presented in this short paper is an explanation of how the Urban Design Studies Unit (UDSU) at the University of Strathclyde in Glasgow has done so, first and foremost conceptually, and then into the practice of what we came to call masterplanning for change.

The body of research that set the basis of our conceptual framework comes from studying urban form as a complex system, which allowed us to describe and analyse it using some key properties typically associated to complex systems - resilience first of all (Feliciotti et al, 2016; Feliciotti, 2017). Resilience, we now know, is an important character of adaptive systems, and therefore of cities themselves. Cities are vulnerable to a wide range of disturbances, and whilst up to very recent years, the discourse on urban resilience has been mostly focused around sudden and unexpected large-scale events, such as natural or anthropogenic catastrophes, more recently growing attention shifted towards other kinds of slow and onset change and how they affect the way urban systems behave over time (Coaffe and Lee, 2016). In complex systems, higher or lower resilience is achieved through synergies emerged from the relationship between all elements that constitute the system itself, and with other interacting systems. Because resilience is a trait that extends through time, the contribution of all parts must also extend through time at multiple scales (Gunderson, 2001). Resilient systems are those that, confronted by change, are able to evolve, change what necessary, learn and re-define themselves through innovation.

\section{What is a resilient urban form?}

When we think of cities, we see that some, entirely or in part, 'work better' than others, having lasted centuries and more, maintaining high functionality and desirability, thanks to minor but continuous adjustments, and little change to their fundamental character. Others, in turn, barely make it past their 10-20th birthday, despite costly, large-scale revamping and facelifts. Our first step in shedding light on this remarkable difference has been to look at the form of the city, with all its physical components, from the smallest to larger ones, from plot to street networks, neighborhoods and districts, as a complex system, and therefore to understand both the relative meanings and traits of each of such components, as well as the rules that tie them together, both in scale (geographically) and in time, from a resilience perspective. We have made substantial progress in this pursuit by combining the precision and definitions of urban morphology to the evidence that we found of the many similarities in how such physical components of urban form have appeared, aggregated and changed in time, a pattern that is recurrent no matter where we observed them, or when they were first established. There are indeed some essential building blocks 
of urban form, on which all the rest relies, that have allowed cities to be functional through time across very different contexts and conditions.

Not unlike other kinds of complex systems, resilient urban forms change and evolve over time at different speed and different scales: according to extensive empirical research in urban morphology (Conzen 1960; Moudon, 1986; Hallowell and Baran, 2013; Kropf, 2018) at any given moment, fewer "permanent" and "stable" features and more "volatile" and "changeable" ones coexist in the spatial fabric of cities: the first set determines the structure of places, affecting their behavior and performance in the long term, whilst the latter is the super-structure, more susceptible and responsive to cues of changes coming from society and context (i.e. lifestyles, preferences, trends...) (Figure 1). It is this dynamic relationship between fast and slow, changeable and permanent that has always enabled cities to respond to challenges of different nature: from local fast-paced changes to large-scale events.

To learn more about this we compared the forms of large number of cities around the world - ancient, medieval, renaissance baroque, industrial, modern and contemporary and informal settlements. Despite each city having unique origins and histories reflected in unique and highly diverse spatial identities, urbanization has maintained a rather consistent pattern, at least up to the advent of professional planning. And because the character of urban form has an impact on how this responds over time, we studied them in relation to their potential resilience capacity applying several proxy indicators of resilience to urban form and its components (Feliciotti et al, 2016; Feliciotti, 2017).

From this line of research (whose findings are summarized in Romice et al, 2017), we learned that at certain points in the history of our cities, the character of their basic morphological components has been altered and, with it, the relationships between them, with profound repercussions on the resilience capacity of the urban form complex. These new urban forms behave as monolithic, rigid collections of isolated physical features, showing reduced propensity to adaptation. Under this light, it is unsurprising that $20^{\text {th }}$ Century planning has been harshly accused to have shaped places and cities which are rigid, possess low resilience and struggle to adapt (Tachieva, 2012).

Whilst our profession has recently developed much greater sensitivity towards the principles of adaptability and sustainability, even the most recent and advanced rhetoric on place making has not yet mastered the design of resilient places: this is because it has never treated its essential ingredient, urban form, as an adaptive complex system itself and because literature on urban resilience literature still tells urban designers little on how to approach the design of the urban form of places.

Whilst this is worrisome, it also makes the search for a solution rather clear: as urban designers, a lot of what we do is by means of masterplans. A widespread view of masterplans, at least developed since early 1950s (Mumford 2009), tends to view them as the symbol of a "blueprint" approach that expresses socially and environmentally heavy-handed and deterministic takes on the production of cities. More recently this negative view has mellowed, thanks to the introduction of principles of flexibility and sustainability in their production. And yet, we need to go much further, turning masterplans on their head, and making them the means to actually deliver change and adaptiveness. But how can we suggest that is it possible to design - to masterplan nonetheless - something that is so complex, something that, by its very nature, constantly changes? And furthermore, it does so at different rates and speed? How can a masterplan be deployed to deliver a place that will, over time, remain vital and viable? 
Figure 1. Slow and fast variables in the urban form in a conceptualisation of overlapping cycles of change at the different morphological scales. More stable and more variable features influence each

other constantly through feedback, and it is this dynamic relationship between fast and slow, changeable and permanent that has always enabled cities to respond to challenges of different nature: from local fast-paced changes to large-scale events
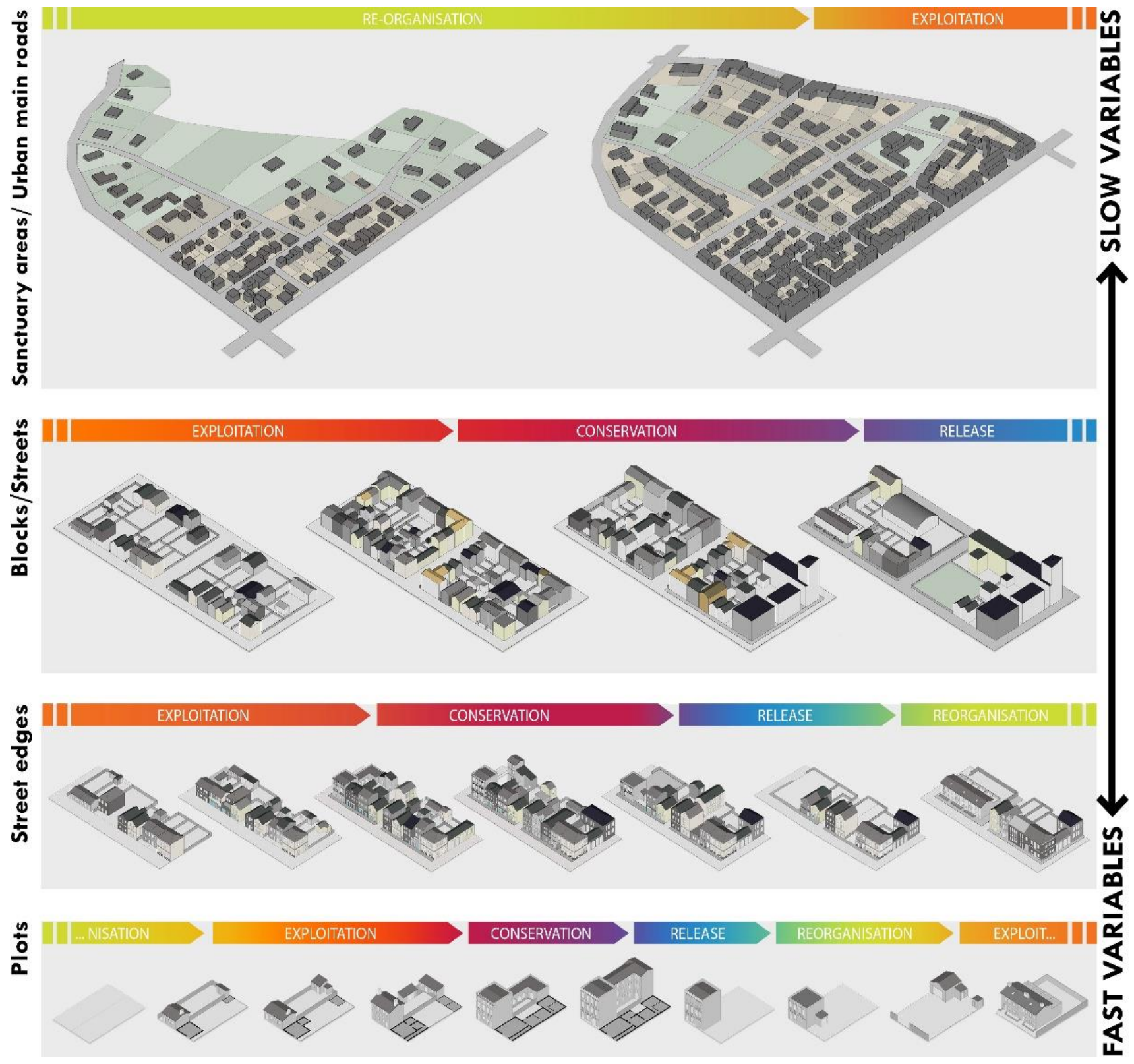

Source: Feliciotti Alessandra, 2018, Resilience and Urban Design: A systems approach to the study of resilience in urban form. Learning from the case of Gorbals. $\mathrm{PhD}$

Thesis, Department of Architectre, Faculty of Engineering University of Strathclyde. 


\section{Masterplanning change}

Some of the best places in the world have been masterplanned: think of Turin, Glasgow, Edinburgh, London, Ferrara (Firley and Groen, 2013; Romice et al, 2017). In all these instances we are talking of masterplans that are clearly different form the ones we are accustomed to today: they were predicated around practical needs. Their principle was simple: often instructed by a landowner whose objective was to derive maximum profit from the development of his/her land, they were shaped around a strong, reliable sub-structure and accompanied with few clear rules to ensure that the execution of all the smaller parts in time, by hands of many, would still reinforce the intended character and quality, and therefore profitability of the whole. Without knowing it, they were designing the city as a complex system characterized at the same time by permanence and changeability, where parts of the system worked in synergy allowing places to change to emerge gradually. though that constant process of adaptation that comes from use and management (Figure 2).

Figure 2. New town plan for Edinburgh, 1767, the largest masterplanning project in the country at the time. The overall layout was drawn by Architect James Craig, whilst individual parcels were acquired by different feuars (individuals holding a feudal tenure of land) often simple tradesmen, masons and wrights, and built by different independent developers and architects. Over time, whilst keeping its majestic character and overall strucure, Edinburgh Town has shown a remarkable capacity to host new functions and accommodate the needs of new users.

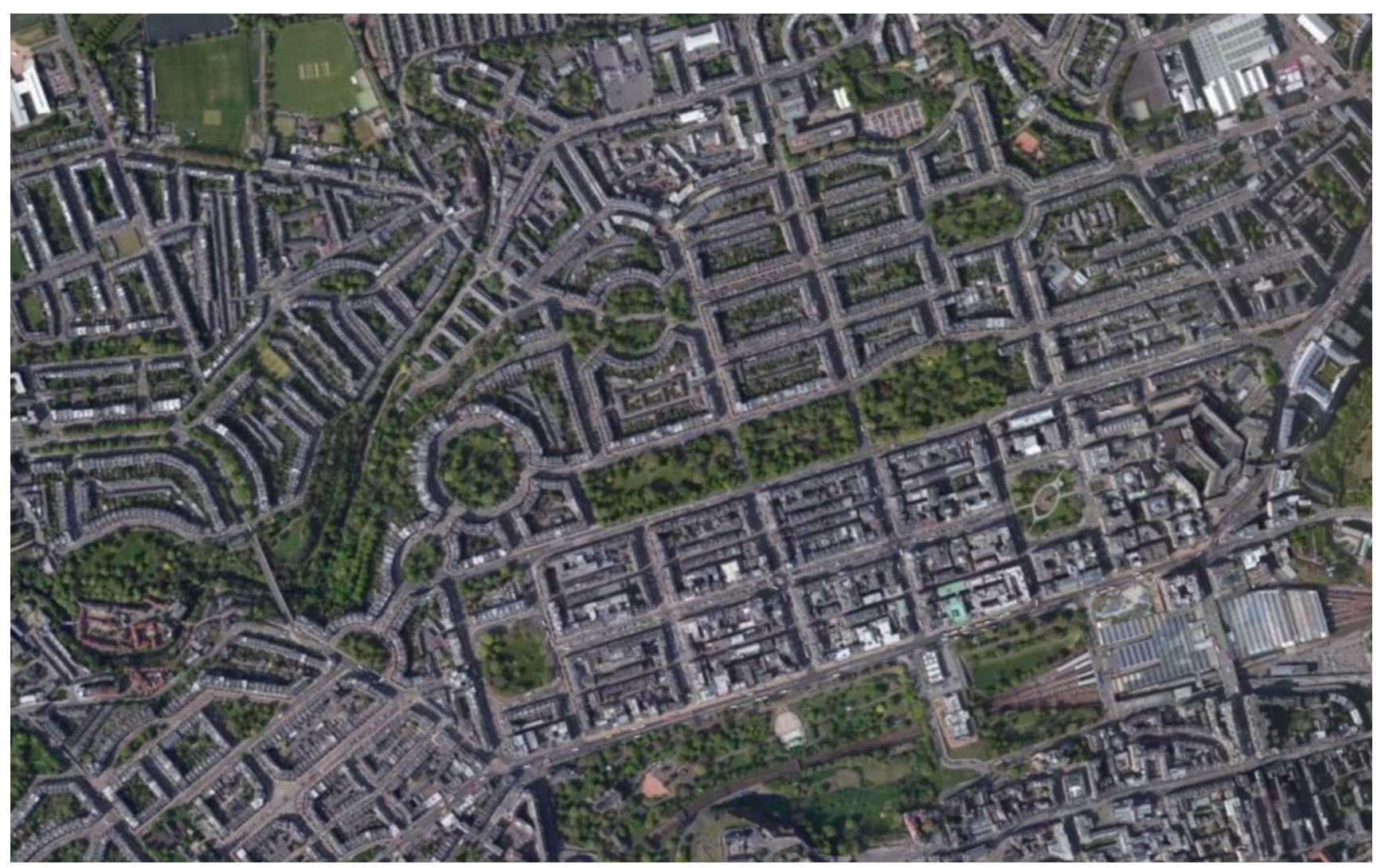

Source: Bing Maps, 2018. Edinburgh New Town. Available through: https://binged.it/2RWYAWg [Accessed 19/11/2018]. 
To achieve this in today's masterplans, fundamentally, we need to reform masterplanning so that this is not seen as an act of creation of final forms, but one of creation of conditions for activities and practices to happen once designers have left. This requires two main shifts. The first is conceptual and entails putting the notion of time at the core of any credible approach to the design of cities and, consequently, that not all the things we design respond to change through time at the same speed or in the same way. The second, which follows from the first, is more practical and entails, based on the fundamental dualism between stability and changeability introduced above, clearly establishing what should be designed-the structure - and what needs not to be designed, or, more poignantly, what should be left to emergence.

The problem with this proposition is defining with a degree of universality, in the bewildering diversity of cities around the world, what is structural. To untangle this problem, we focused on those features that make cities similar to each other, leaving aside what makes them different, and formalised an approach to masterplanning that predominantly focused on features of the first kind - not because what makes them unique is not important to us, but, quite on the contrary, exactly to preserve that uniqueness from us. Our idea of masterplan is that of a plan that defines networks of streets, hubs/nodes of activity, that provides a rough idea of density and that defines building typologies, always ensuring an overall integration and compatibility between all these elements. It then sets the linkage rules between these main essential elements of greater permanence and the smaller ones - the plots and their aggregation, implementing a precise design link between hierarchy of streets, street edges and plots (Figure 3). In our approach, urban blocks are no longer design units, nor are neighbourhoods; instead, the design of urban fabric follows street importance, through street edges that make up blocks and are themselves made of disjointed plots - this last being the key ingredient of a time sensitive adaptive city which follows the rules of complex adaptive resilient systems. This is, to us, adaptive design or, as we like to call it, Masterplanning for Change (MfC).

Ultimately, the objective MfC is to set out, through a series of steps, the spatial structure - as defined above - that, once in place, will enable the evolution of the spatial system over future generations in a way that maintains its long-term resilience. In this sense, its aim is not so much to design "beautiful" places straight away but, crucially, to establish the basic framework within which everything that we do not design can emerge over time, allow qualities to emerge and be maintained over generations. MfC seeks to contribute to support the amazing complexity of cities in the urbanization age. Whilst this short article does not give us the opportunity to explain the details of our method, the interested reader is invited to look at our Chapter published in the book "Rethinking Masterplanning: Creating Quality Places", where the method is explained in greater detail, as well as how it redefines the way we designers can help cities adapt and improve over time. 
Figure 3. Three main strategic and design output of the MfC approach: the Concept Plan (top left), a design tool that addresses the area to masterplan in relation to density, street and transport network, ecological network and clusters of services, incorporating strategic considerations; the Foundation Masterplan (bottom left) a propositional document that gives precise form to the Concept Plan, by attributing density ranges, services, and character to each street edge, according to a place-specific Local Urban Code, a catalogue of local forms showing how plots and building types are shaped and assemble across different conditions; and the Masterplan (right), which takes further the design of street edges, blocks, streets, public spaces and ecological network.
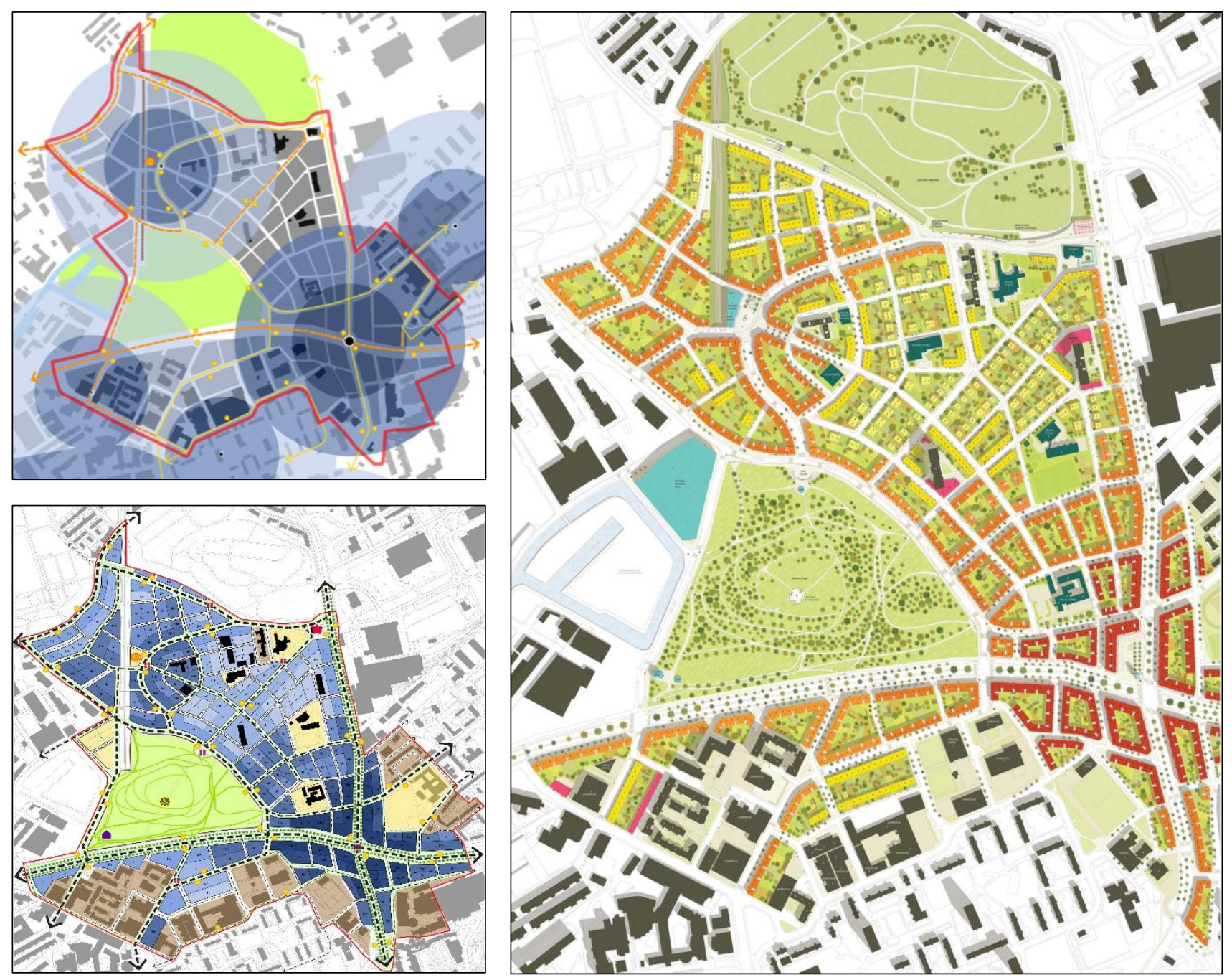

Source: Design proposal for Sighthill, in Glasgow, students of the Masters in Urban Design at the University of Strathclyde, 2012.

\section{Conflict of Interest}

The authors declare no conflict of interest

\section{No references for the short papers but hyperlinks within the text}

(C) 2018 by the authors; licensee MDPI and IFoU, This article is an open access article distributed under the terms and conditions of the Creative Commons Attribution license. 